\title{
The Research on Influence Results of Tailings Dam Break Based on 3D Points Cloud Data
}

\author{
Shuai ZHOU ${ }^{1, a}$, Fu-qiang $\mathrm{SHI}^{1,2}$, Guo-chao $\mathrm{MA}^{2}$, Xiao-hua HUANG ${ }^{3}$ \\ ${ }^{1}$ Mechanical Engineering College, Southwest Jiaotong University,Chengdu,China \\ ${ }^{2}$ Sichuan Academy of Safety Science \& Technology,Chengdu,China \\ ${ }^{3}$ China Railway Eryuan Engineering Group Co.Ltd,Chengdu,China \\ azstotem@foxmail.com
}

Keywords: 3D points could data; DEM; tailings dam break; debris flow

Abstract:Some residential areas and factories are located downstream the tailings pond. Once the tailings dam collapsed, the consequence will be very serious, so perfect prevention and emergency preparedness work is critical. And the prediction of tailings dam collapse affecting consequence is an important basis for the work. To improve the predictive accuracy of tailings dam break consequence, accurate topographic boundary data is necessary. Thus, precise terrain scanning was implemented by using 3D laser scanner for the tailings pond and downstream. Then higher precision digital elevation model was generated after the process of three-dimensional points cloud data denoising, splicing and modeling. On this basis, combining with the tailings dam geological prospecting and design data, the numerical model of dam break flow was set up. As a result, the residential area and the farmers' market planned to build were completely destroyed once the tailings dam break. With the calculation based on the 3D points cloud data, scientific decision basis can be provided for related departments.

\section{Introduction}

With the rapid development of economy in China, a number of tailings ponds were resulted from the large-scale mining activities of mineral resources. By the end of 2012, the number of all kinds of tailings ponds was more than 12,000 in China $^{[1]}$. Tailings pond is one of the major hazards in mines, and the accident damage by tailings ponds is in $18^{\text {th }}$ of 93 kinds of accident or potential hazards ${ }^{[2]}$.The tailings dam as a special industrial structures, is composed of initial dam and tailings stacking dam. Generally,stacking dam is higher in the whole dam. Once tailings dam break happened,it will produce a large number of fluid, which is similar to the debris flow. Dambreak debris flow can directly endanger the downstream factories,other facilities, and residential areas. The result causes serious personal casualty,property loss and social influence.Since 2001, a total of 53 tailings pond accidents were happened in China, killing 351 people. Due to historical reasons, a lot of early construction of the tailings pond was not taken seriously, until the frequent accidents and a series of serious consequences, whose security problems are increasingly focused on. Thus, the technical data of many tailings ponds is not complete.And many small and medium-sized tailings ponds were not been properly designed. Because the improper location, living area, workshop facilities or town were built downstream the majority of the tailings ponds. In the events of accident, the consequences will be more serious.

The security problems about tailings ponds were studied by many researchers at home and abroad. The researches were mainly concentrated on the disaster and risk of dam break ${ }^{[2-4]}$, security evaluation and guarantee system ${ }^{[5]}$, accident statistics and analysis ${ }^{[6]}$, monitoring and early warning ${ }^{[7]}$, tailings dam slope stability analysis and the failure mechanism ${ }^{[8]}$, physical and mechanical properties of tailings ${ }^{[9]}$,etc. Some achievements were gained from these special technology researches, which can improve the safety level of the tailings pond.But the study of the influence results on dam break was generally carried out by some empirical formulas of flood or debris flow. The calculation of dam break flow running out was based on the simplified terrain boundary conditions. And the research based on 3D real terrain was rare. Quantitative analysis of dam break influence results is a very important research direction in safety risk on tailings dam. The research results can provide scientific 
decision basis for the reservoir location, emergency rescue ,and disaster prevention, etc.As a result, the research on quantitative analysis of dam break influence results is necessary and important.

The terrain data of tailings pond and its downstream is very important basic factor influencing the accuracy of the predicting work on dam break influence results. A lot of old tailings ponds are lack of original terrain data. Even new built tailings ponds, the terrain data is not good enouth because of the data got by total station, GPS and other single point measurement tools. The shortcoming of the data got by the conventional measuring method is less measurement points, lower efficiency,and lack of resolution.For this purpose, 3D laser scanner of high precision, high density, high speed and without prism,can be used to obtain the millions of three-dimensional points cloud data for the tailings pond and downstream surface.Then digital elevation model (DEM) is generated by the high resolution terrain data, which can provide accurate terrain boundary conditions for the tailings dam break debris flow. However, the accurate terrain data is just the foundation for forecasting the influence results of the tailings dam break. Numerical methods can be carried out in the research on the tailings dam break results in addition to using the empirical formula. Considering the nature of tailings dam break flow is similar to the mud debris flow, therefore, the FLO2D calculation software was introduced in the research.The software was officially accepted by the USA federal emergency management agency (FEMA) and the European countries .

\section{The Research Background And 3D Points Cloud Data}

\section{The Information Of Tailings Pond And And Research Background.}

One tailings pond studied is in the city of Panzhihua,China.The total dam height designed is 110 meters, and the total capacity is $11,642,500$ cubic meters, so the tailings pond is belong to the second-class one.Now the tailings dam was built up to the elevation height of 1,400 meters. Residential area is 750 meters distant downstream the tailings dam, and a farmer's market is planned to built by the local government.Therefore, the research team was invited by the local safety supervision department to calculate the influence results of the tailings dam break. The consequences of the calculation can be consulted to make scientific decisions. The main parts of tailings pond are as follows: (1) The initial dam: permeable earth-rock mixed dam, dam crest elevation is 1370 meters, and the dam bottom elevation is 1340 meters. The upstream slope of dam is $1 / 2$, the downstream slope of dam is $1 / 2.5$.(2) Stacking dam:built by the method of upstream damming, every subdam is 2.5 meters high, the upstream slope of dam is $1 / 2$, the downstream slope of dam is $1 / 4$, and the average slope of stacking dam is $1 / 5$. (3) Flood drainage system: adopt the system of "discharge tower-shaft-branch discharge tunnel-main discharge tunnel"; the cross section of main discharge tunnel is 5.5 meters by 6.94 meters; the cross section of branch discharge tunnel is 2.0 meters by 2.5 meters; the shaft diameter is 1.8 meters.(4) seepage system:a blind drain is set up every 10 meters above the top initial dam..In addition,flood catching channels were built on the dam shoulder,drainage channels were built on the dam slope, displacement and seepage line observation facilities were set up, etc.

3D Points Cloud Data of the tailings pond.

3D points cloud data for the tailings pond was obtained by the 3D laser scanner of I-site 8810 , and combined with high precision leica GS14 GPS positioning system. The scanning work was taken over six days and 63 stations were set.And The 3D points cloud data(shown in Fig.1) of the tailings pond and its downstream was processed by matching, denoising and filtering, then the digital elevation model(DEM) of the tailings pond area was generated (shown in Fig.2). 


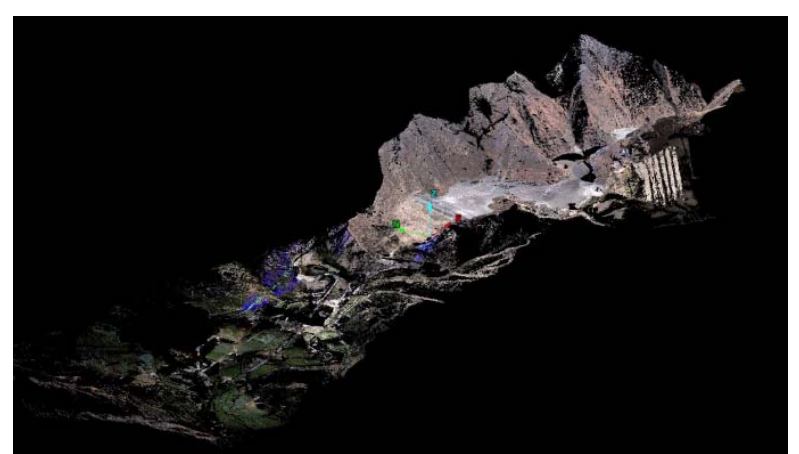

Fig.1 3D laser scanning points cloud

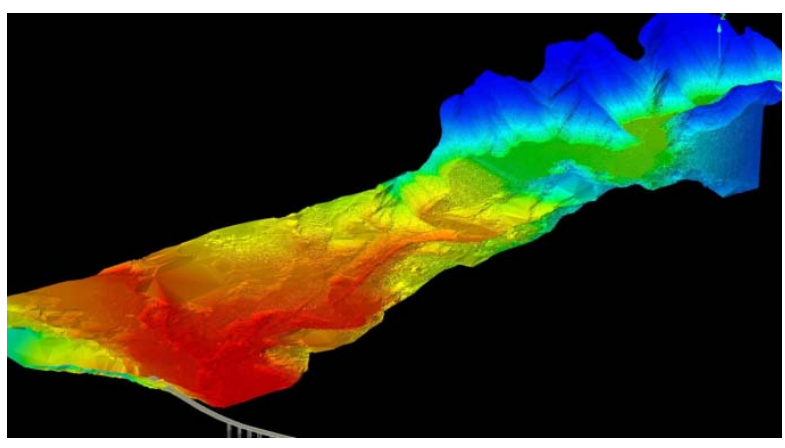

Fig.2 DEM based on 3D sannning data

\section{The Calculation Of Tailings Dam Break Influence Results}

\section{The Calculation Parameters Setting Of Dam Break.}

The accuracy of the digital elevation model(DEM) of the tailings pond area was high, and the resolution of it was chosen by 1:2000.Then,the DEM was converted to digital matrix model as a foundation for numerical simulation model, as shown in Fig.3.

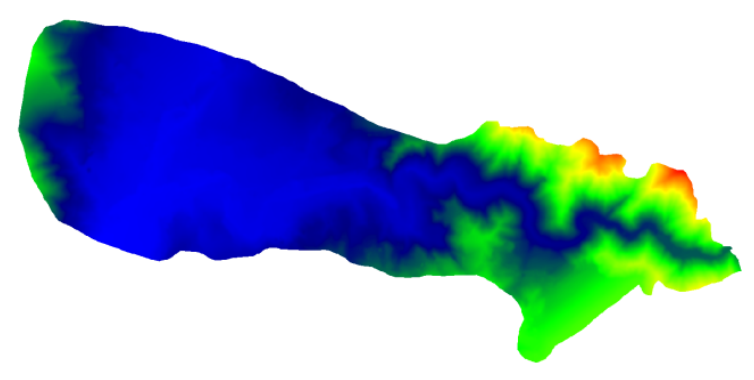

Fig.3 Numerical simulation model

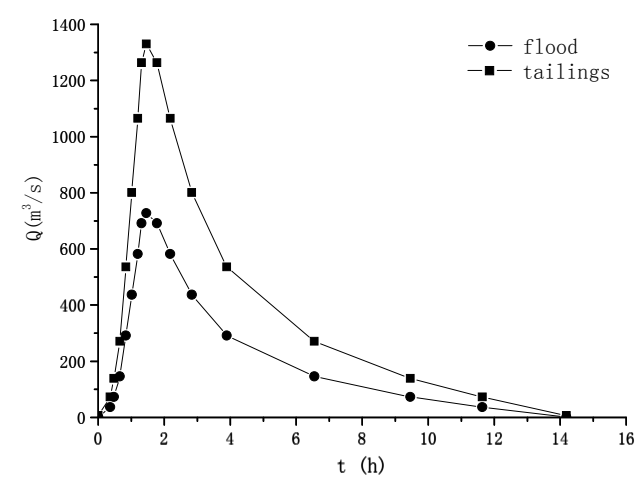

Fig.4 Debris flow process curves of dam break

According to the terrain data and local storm flood parameters ,the flood parameters was calculated(shown in Table 1 ).

\begin{tabular}{cc} 
Table 1 The flood parameters calculated & \\
\hline $\mathrm{P}(\%)$ & 0.1 \\
Peak discharge $\left[\mathrm{m}^{3} / \mathrm{s}\right]$ & 20.07 \\
Flood volume $\left[10^{4} \mathrm{~m}^{3}\right]$ & 21.04
\end{tabular}

For the tailings pond, flood and total tailings are the most major suppliers of water body and loose solid material.According to the actual survey and calculation by $3 \mathrm{D}$ points cloud data, the capacity of the loose solid material of the tailings pond is about $6,150,000$ cubic meters, and the water capacity is about 5,500,000 cubic meters. Combined with the simulated frequency flood volume, the total volume can be set for the calculation of fluid.According to the formula of debris flow and FLO-2D fluid concentration reference value, the debris flow density was set value as 0.55 . Integrated with the flood calculation,the debris flow process curves of dam break was calculated in $0.1 \%$ of flood frequency at the cases of tailings dam completely breaking one moment (Fig.4).

On the basis of determination about the flow movement process and the total volume of the dam break, the actual landscape,the surface environment and physical state of the debris flow were carefully analysed.After the analysis course,some fluid parameters such as viscosity coefficient, laminar flow retardation factor,proportion of the sediment,manning coefficient and so on were selected(shown in table 2). The viscosity coefficient $\eta$ and yield stress $\tau_{y}$ are control parameters determining the working characteristic of the fluid.And the these two types of parameters are closely connected with fluid volume concentration $c_{v}$.

$$
\eta=\alpha_{1} e^{\beta_{1} c_{v}}
$$




$$
\tau_{y}=\alpha_{2} e^{\beta_{2} c_{v}}
$$

$\alpha_{1}, \alpha_{1}, \beta_{1}, \beta_{2}$ are empirical coefficients.

Table 2 Numerical calculation parameters selected

\begin{tabular}{ll}
\hline Dam break mode & The entire sudden break \\
\hline The start place & The top of the dam \\
Volume concentration $c_{v}$ & 0.55 \\
The resolution of dem & $1: 2000$ \\
Manning coefficient & $0.07 \sim 0.25$ \\
Flow process & Fig. 4 \\
Flood frequency[\%] & 0.1 \\
Proportion of the sediment $\left[t / \mathrm{m}^{3}\right]$ & 2.25 \\
Laminar flow retardation factor & 2280 \\
$\alpha 1$ & 0.811 \\
$\beta 1$ & 13.72 \\
$\alpha 2$ & 0.00462 \\
$\beta 2$ & 11.28 \\
\hline
\end{tabular}

The Analysis For Calculation Results Of Tailings Dam Break.

FLO-2D model is a fluid calculation software based on two-dimensional grid. The fluid flow state (direction and speed)can be computed in each grid according to the comparison between the fluid characteristics and the actual terrain, so the submerge condition of fluid in each grid is determined. At last, the final submerge depth and velocity of the flow can be obtained from the results of the calculation in research area(Fig.5 and Fig.6).At the same time,the research in the paper was carried out at the extreme case of entire sudden dam break. Therefore, the most serious disaster influence results caused by tailings dam break debris flow was present.

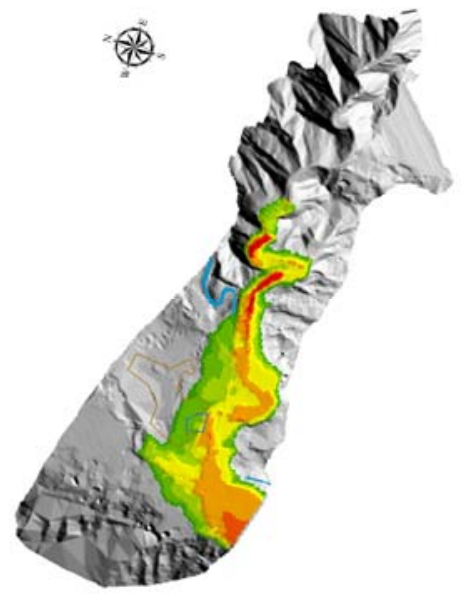

Fig.5 Submerge depth profile

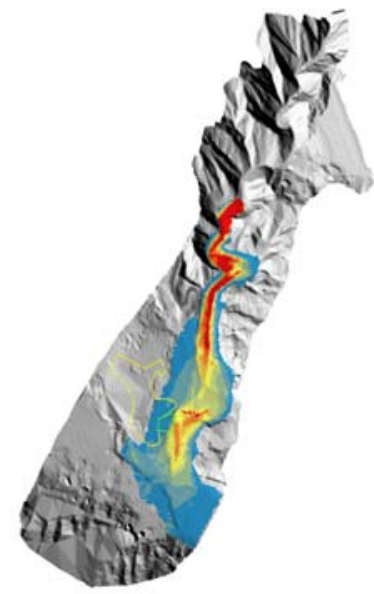

Fig.6 Velocity profile

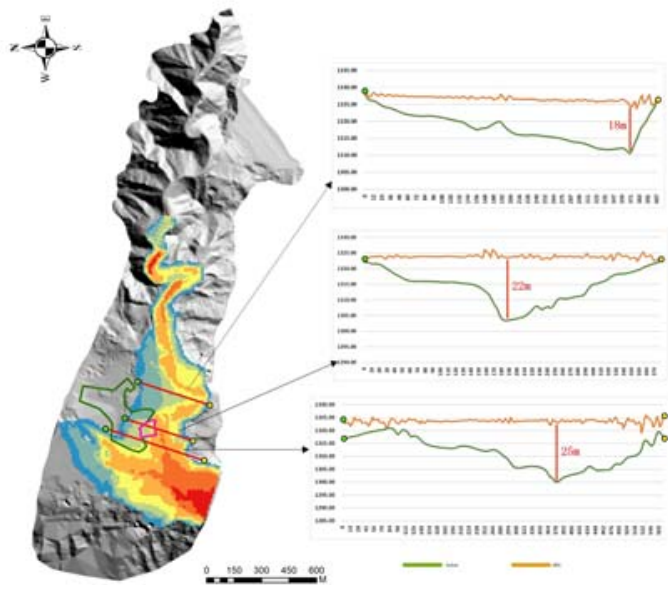

Fig.7 More details with cross sections

According to the above calculation results, the area of nearly 18,985 square meters downstream the tailings dam were buried by the dam break debris flow in $0.1 \%$ of flood frequency. The residential area and the farmers' market planned to build were completely destroyed once the tailings dam break. Moreover, the largest thickness of the sediment was up to 28 meters in the channel downstream the dam. The sediment caused by debris flow in the center of channel was higher than both sides. In terms of velocity on dam break debris flow, the maximum velocity was up to $32 \mathrm{~m} / \mathrm{s}$, and the average flow velocity was at about $15 \mathrm{~m} / \mathrm{s}$ in the channel. In other words, according to a preliminary calculation of the distance, the debris flow arrived the residents living area only in 100 seconds. The emergency time was too short to take actions for the residents downstream the tailings dam. 
More details can be got from the dam break calculation for the specific buried situation of residents living area and the farmers market planned to build. As a reference to the original terrain, three cross-sectional analysis(Fig.7) were obtained on the basis of calculation results. The original channel was deposited by the sediment caused by the debris flow, and the thickness of sediment was up to 20 meters or so. Obviously, the serious results could cause devastating damage to residential buildings.

\section{Conclusions}

The research on influence of tailings dam break was carried out based on the real terrain data from $3 \mathrm{D}$ points cloud data for the first time. And the calculation results can be provided as the basis for the local safety supervision department and tailings pond organization to make decisions.

(1) The high precision digital elevation model(DEM)was obtained based on the 3D points cloud data first time in tailings dam break research. combined with the design data of the tailings pond,the DEM can be provided accurate terrain boundary conditions for the dam break calculation.(2) Using the calculation model built based on the 3D points cloud data, the debris flow of tailings dam break was calculated by Flo2D. The results show that the area of nearly 18,985 square meters downstream the tailings dam were buried by the dam break debris flow. The residential area and the farmers' market planned to build were completely destroyed once the tailings dam break.(3)The research team advised to move downstream residential area, and the farmers market planned should be resumed new location. In order to reduce the loss rate,the blocking dam should be added in the right place downstream the tailings dam.

\section{Acknowledgements}

This work was financially supported by Sichuan province science and technology support project(12ZC1861) and International cooperation project of science\&technology department of Sichuan province(12GH0005).

\section{References}

[1] Zhang Li-Ting.Journal of Hydraulic Engineering, 2013, 44(05): 594-600.

[2] Peng Kang,LI Xi-bing,WANG Shi-ming,et al.Journal of Central South University(Science and Technology), 2012, 43(04): 1447-1452.

[3] Wang Jin-Miao, Jia Ming-Tao,Wang Jian,et al. Risk evaluation of break-dam in tailings reservoir based on matter-element extension model[J]. Journal of Safety Science and Technology,2014, 10(04): 96-102

[4] Li Quan-Ming,Zhang Xing-Kai,Wang Yun-Hai,et al. Journal of Hydraulic Engineering,2009(08): 989-994.

[5] Wang Ying-bo, Wang Lin,Li Zhong-xue.Systems Engineering-Theory \& Practice, 2012(11): 2585-2590.

[6] Rico M, Benito G,Salgueiro A R,et al.Journal of Hazardous Materials, 2008, 152(2): 846-852.

[7] Zhang Deng,Jian Wen-Bin, Ye Qi ,et al. Rock and Soil Mechanics, 2014(03): 835-840.

[8] Zhang Duo,Liu Yang, WU.Shun-Chuan,et al.Chinese Journal of Geotechnical Engineering, 2014(08): 1473-1482.

[9] Zhang Zhi-jun,Li Ya-jun,He Gui-cheng,et al.Rock and Soil Mechanics,2014(06): 1561-1568. 